\title{
The Sequence of Acquisition of Personal Pronoun Case and Person Reference among 6 Year Old Children in Two Selected Malaysian Kindergartens
}

\author{
Arshad Abd Samad (Corresponding author) \\ Faculty of Educational Studies, Universiti Putra Malaysia, 43000 Serdang, Selangor, Malaysia \\ E-mail: arshad@upm.edu.my \\ Nurul Iman Arshad \\ Faculty of Education and Languages, HELP University, 50490 Kuala Lumpur, Malaysia \\ E-mail: niarshad@gmail.com
}

Received: 10-12-2016

Accepted: 28-01-2017

Advance Access Published: March 2017

Published: 01-05-2017

doi:10.7575/aiac.ijalel.v.6n.3p.273

URL: http://dx.doi.org/10.7575/aiac.ijalel.v.6n.3p.273

The research is financed by The National Child Development Research Centre, Universiti Pendidikan Sultan Idris, Malaysia 2015-0079-107-04

\begin{abstract}
Pronoun case and person reference refer to the position of the pronoun in the sentence and the person the pronoun refers to respectively. Examining the acquisition of pronoun case and person reference among young children can be insightful as, besides their obvious relevance to language development, both these constructs can have implications on other aspects of child development. Attention given by children to these various constructs may indicate the importance children place on the concept of ego and self as well as on social relations. The sequence of acquisition of personal pronouns among these children is therefore an important phenomenon to be examined as it can reflect linguistic and socio-cognitive development. This largely descriptive study examines the sequence of acquisition of the English pronouns among forty 6 year old Malaysian children learning ESL in two kindergartens. The children in the study were presented with 33 drawings to assess their familiarity with case and person reference expressed through English personal pronouns. They were required to select the correct pronoun from three pronouns that were used to describe each drawing. This paper reports on the accuracy rates for each pronoun and assumes that high accuracy rates indicate a more complete acquisition of the pronoun. Error forms by the children were also be identified and examined. Data obtained were compared to acquisition sequences in the literature and general implications related to the acquisition of personal pronouns among children in an ESL setting in Malaysia will be discussed.
\end{abstract}

Keywords: ESL, Acquisition sequence, Pronouns, Language Teaching in Malaysia, Kindergarten

\section{Background of the Research Problem}

Language structures that are acquired early by children can inform educators of factors that can impact the rate of acquisition of the language. Second language acquisition studies have carefully observed how children acquire the second language. Many of these studies, however, have been conducted in the target language environment. The Malaysian context provides a second language environment where the target language is not always often used, encouraged, nor even necessary. In many situations and for many families in Malaysia, English language is a foreign language with limited opportunities for use. Nevertheless, mastery of the English language is highly valued in the country and is therefore taught formally at all levels of education.

The teaching of languages in Malaysian kindergartens exposes children to at least two languages, most often the student's mother tongue and the English language. This situation can cause some confusion amongst the children if the same teacher is involved (Abdullah et al., 2015). Abdullah et al. (2015) also raise the concern that switching of languages contradicts pedagogical principles where children should have a "structured environment that provides them stability and security" (p. 129). In such a situation, mastering the English language may become unnecessarily more difficult and fossilization of inaccurate forms may also occur. It is therefore important to understand how often used grammatical structures are acquired in order to provide a more structured environment where students can be systematically exposed to the second language.

At the pre-school level in Malaysia, no structured curriculum has been suggested in terms of how specific aspects of the English language such as grammatical structures should be presented to the children. Although a comprehensive curriculum for the English language may not be necessary at the pre-school level due to the more experiential, actionrelated and thematic approach that is more appropriate for young children, some grammatical systems are especially 
relevant and should be given greater consideration in terms of how they should be presented. One such system is the personal pronoun.

Personal pronouns represent a very structured language sub system in the English language and convey various meanings and concepts. There are eight English pronouns (I, we, she, he, it, they, you, and plural you) that take various forms based on their role and meaning in a sentence (e.g. subject, object, number, person, gender, possession and reflexivity). In learning a second language, Rispoli (2005) believes that young children may have complete mastery over some forms but only a vague understanding of others. In this respect, for example, Wong and Liu (2008) contend that number and person are easier concepts to master compared to case and should therefore be taught earlier. Additionally, some English pronouns - most notably the objective possessive pronouns (e.g. mine, his, hers) - do not have an equivalent in most of the native languages of children in Malaysia. A study of this nature among young children at this age will therefore not only allow for the researcher to examine whether difficulty in construct will affect acquisition sequence but also the kind of inaccurate forms that may appear in their developing language systems. From a pedagogical perspective, this can help teachers and educational planners develop preventive measures to prevent fossilization of incorrect forms.

The English language personal pronoun system is especially relevant for pre-school students in acquiring English as a second language. Imbued within this system are notions of personal ego and how children can express and make reference to their own selves; socialization with peers and others; as well as potential indications of language development. Nevertheless, in order to understand how best to present or expose the English personal pronoun system to Malaysian children whose first language is not English, there is a need to understand the level of mastery of the system among these students as well as aspects of the system that may pose difficulty to the students. How the pronouns are used, how accurately they are used and the kinds of errors that occur can also provide important information regarding a child's processing of the language. Similarly, the sequence of acquisition of personal pronouns can provide insights into the second or foreign acquisition process among young children in Malaysia. Consequently, efficient teaching and learning opportunities can be created.

\subsection{Research Objectives and Research Questions}

The objective of this research is to examine the use of English language personal pronouns among young Malaysian children learning English as a Second Language (ESL). More specifically, it intends to document whether the acquisition of personal pronouns occurs in any specific sequence or pattern as well as specific problems that young children face in acquiring English personal pronouns. It is also hypothesized that the acquisition of pronouns may show a similar pattern as described by various studies done especially on first language learners (see e.g. Owens Jr., 2008). Additionally, this study aims to identify pronoun error forms common to the children in this study. Implications and recommendations will focus on teaching and learning personal pronouns to young children.

The research questions of the study are:

1. What are the English language personal pronouns that are used by young children (5-6 years old) in Malaysia?

2. What non-standard forms of English language personal pronouns are observed among young children in Malaysia?

3. Does a pattern emerge in the accurate use or acquisition of the different kinds of English language personal pronouns among young children in Malaysia.

\section{English Language Personal Pronouns}

A traditional definition of a pronoun is that it is a closed class word that is used to replace nouns (Berry, 2012). While there are various types of pronouns such as the relative pronoun (e.g. who, that, whom), the interrogative pronoun (e.g. who, which, what), and the demonstrative pronoun (e.g. this, that, those), the personal pronoun is "the most important class because they are the most common and can vary in a number of ways, some of which are unique to English" (Berry, 2012). Table 1 below contains all the English language personal pronouns including the possessive adjective pronouns.

Table 1. English language personal pronouns

\begin{tabular}{llllll}
\hline Person & Subj Pro. & Poss Adj & Poss Pro. & Reflexive Pronouns & Obj Pro. \\
\cline { 1 - 1 } \multicolumn{1}{l}{ Singular Forms } & & & & & \\
$1^{\text {st }}$ & I & My & Mine & myself & me \\
$2^{\text {nd }}$ & You & Your & Yours & yourself & you \\
3rd (m) & He & His & His & himself & him \\
3rd (f) & She & Her & Hers & herself & her \\
3rd (In.) & It & Its & Its & Itself & it \\
Plural Forms & & & & & \\
$1^{\text {st }}$ & We & Our & Ours & Ourselves & us \\
$2^{\text {nd }}$ & You & Your & Yours & Yourselves & you \\
$3^{\text {rd }}$ & They & Their & Theirs & Themselves & them \\
\hline
\end{tabular}


Table 1 includes references to technical terminology such as person, subjective and objective pronouns, possessive adjectives, possessive pronouns and reflexive pronouns. The subjective and objective pronouns refer to the position of the pronouns in the sentence with the two pronoun forms appearing at the beginning as a subject or at the end as an object respectively. Reflexive pronouns are described by Berry (2012) where "the subject and the object are the same" as in $I$ hurt myself (p. 85). Two other concepts that are important in discussing pronouns used in Table 1 are case and person reference, and they will be discussed in the following section.

\subsection{Case and Person Reference}

Three cases are relevant to pronouns, namely the nominative, accusative and genitive case depending on the role they play in the sentence. A pronoun in the nominative case refers to a pronoun that acts as the subject in the sentence and is often referred to as a subjective pronoun. The accusative case refers to pronouns that appear in the object position and is also known as the objective pronoun. The third case, the genitive case, refers to possessive pronouns such as mine, yours and his in the table above. These possessive pronouns occur after the nouns that they possess. However, a different form of possessive pronouns that occur before the noun as in my table and your pencil are often referred to as possessive adjectives rather than pronouns. This is because they only occur with nouns and are therefore dependent on the nouns that follow, much like an adjective that occurs together with a noun.

Pronouns can also refer to different persons in a conversation and can act as a deictic or pointing tool. Berry (2012) describes person as a way to "refer to different participants in the speech / writing situation" (p.83) with the first person referring to the speaker or writer, the second to the listener or reader and the third to all other people and things outside the act of communication. In English, person reference refers to the first person, second person and third person. The first person refers to the person speaking while the second person refers to the person spoken to. The third person refers to another person who is being referred to by the first and second persons in a conversation. In addition to these three person references, gender (male or female) as well as number (singular or plural) are also important concepts.

\subsection{Studies on the Acquisition of Pronouns}

Studies on the acquisition of personal pronouns will be discussed according to two broad emphases. The first is the development of the personal pronoun system among children and the second is the error forms that often occur among children.

\subsubsection{Development and acquisition of personal pronouns}

Various studies have been done on the acquisition of English personal pronouns (e.g. Cruttenden, 1977; Morehead \& Ingram, 1973; Morgenstern, 2012; Rispoli, 2005; Waterman \& Shatz, 1982). Based on these studies, Owens Jr. (2008) provides an approximate time frame for acquiring English personal pronouns among young children who speak English as their first language. This sequence is illustrated in Table 2 below.

Table 2. Approximate age of children when acquiring personal pronouns

\begin{tabular}{ll}
\hline $\begin{array}{l}\text { Approximate Age } \\
\text { (in Months) }\end{array}$ & Pronouns \\
\hline $12-26$ & I, it (subjective and objective) \\
$27-30$ & My, me, mine, you \\
$31-34$ & Your, she, he, yours, we \\
$35-40$ & They, us, hers, his, them, her \\
$41-46$ & Its, our, him, myself, yourself, ours, their, theirs \\
$47+$ & Herself, himself, itself, ourselves, yourselves, themselves \\
\hline
\end{tabular}

Sources: Adapted from Haas \& Owens (1985); Huxley (1970); Morehead \& Ingram (1973); Waterman \& Schatz (1982); and Wells (1985).

In learning a second language such as the learning of English in Malaysia, however, the sequence of acquisition of English pronouns among children is unclear. Given that formal learning may begin at age 4 or 5 , it is useful to determine whether the same acquisition sequence as suggested above for children and their first language will also emerge in learning English as a second language.

Various hypotheses have been proposed to help explain relevant factors that influence the acquisition of pronouns. Charney (1980) examined the phenomenon of pronoun reversal among children and suggested various explanations for the phenomenon. Pronoun reversal involves, for example, the use of the second person pronoun (i.e. you) to refer to the first person (i.e. $I$ ) and is sometimes observed in a child's developing language system. Hence, in a conversation where the child is referred to as you, the child may respond by referring to himself or herself as you as well. Although Morgenstern (2012) considers pronoun reversals "a minor phenomenon, and quite rare", she notes that "it does seem to play a significant role in the mastery of the pronominal system" (p.58). It is also noted pronoun reversal is frequently observed in language disorders and physical disabilities. Fraiberg and Adelson (1977), for example, point to instances where blind children who are capable in all other respects, often reversed pronouns well into age five, largely they argue 
due to difficulties they face in forming a concept of self without the visual modality. Pronoun reversal may also occur due to an egocentric view adopted by the child, whether the child is precocious or reserved in the use of language (Dale and Crain-Thoreson, 1993), or the child trying to speak from the addressee's perspective (Chiat, 1986). Charney (1980) also refers to the person-in-speech role referring theory, where only pronouns that are relevant to the child are understood by the child. Therefore, the child may be able to use the pronoun $I$ correctly to refer to himself but may not understand why $I$ is also used by someone else when he speaks about himself.

\subsubsection{Error Forms}

Studies conducted on error forms are often based on the belief that error forms reveal how language is being processed. In learning a second language, comparisons are also made with the native or first language as there may be interference errors caused by the first language system. A second concern related to errors is that some errors may be more habitual and long lasting - formed early and becoming fossilized or habitual even until late in life. Identifying errors early, therefore, can help prevent these errors from becoming habitual.

There is anecdotal evidence from teachers regarding error forms in English personal pronouns among Malaysians. Additionally, language corpora such as the English of Malaysian School Students (EMAS) Corpus also provide further evidence of errors.

Some erroneous forms Malaysian students produce when using English personal pronouns can be identified based on anecdotal evidence. For example, the possessive pronoun mine is often replaced by the phrase my one as in the phrase * That book is my one. To a lesser extent, other personal pronouns such as his and her are often also incorrectly followed by the noun "one" to show possession.

Language corpora, which contains extensive examples of language use, can provide instances of error forms in the use of pronouns. In a brief survey of essays written in the EMAS Corpus (Arshad et al., 2002) by Malaysian Standard 5 students, for example, several errors in the use the first person singular, third person singular and plural pronouns can be noted. Some of these error forms include the following with the correct pronoun provided in parentheses:

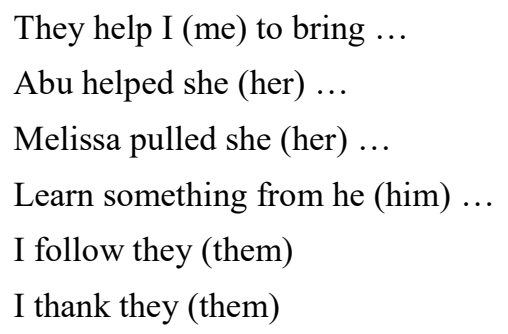

The errors in the six phrases above show that the students were not able to provide the correct objective personal pronoun form, as presented in the parentheses, and used the subjective form instead. It should be noted, however, that as the corpus is a written corpus, other errors found involved confusing pronouns with non-pronoun forms that are pronoun homophones. Some examples are the use of their for there as in over their; and their for they're as in when their back.

Finally, it should be noted that it is useful to determine how frequently a pronoun form is used as it can indicate the extent of exposure children may have to the form. Similarly, frequency of use also signals the importance of a pronoun form as less frequently used pronoun forms may not need as much emphasis in teaching compared to those that are frequently used. Finally, the probability of identifying error forms may also be less likely with low frequency pronoun forms. In the sample EMAS corpus, the most often used forms are the pronouns in subjective position, followed by possessive adjective pronouns, pronoun forms in the objective position, and the possessive and reflexive pronoun forms.

\section{The Study}

The design of this study was generally descriptive and intended largely to determine student ability in the use of English language personal pronoun forms through the use of an elicitation task, observation and teacher response to interviews and a questionnaire. Accuracy rates on the elicitation task were considered to reflect acquisition and this was triangulated with information from teacher feedback during interviews and their observation of the students using a checklist. Both case and person-reference in English personal pronouns are specifically examined in terms of how these constructs may influence acquisition.

In this study, only the thirty three pronouns in Table 3 were examined. Subject, object and possessive pronouns refer to the nominative, accusative and genitive cases respectively. Both the possessive adjectives and the reflexive pronouns are also included in the study because of their close connection to the pronoun forms and the meanings they indicate. Person is examined in terms of the first, second and third person pronouns, all of which can be in either the plural or singular forms. However, number (i.e. singular or plural) was not given specific attention in this study. 
Table 3. Pronouns examined in study.

\begin{tabular}{|c|c|c|c|c|c|}
\hline Person & Subj Pro. & Poss Adj & $\begin{array}{l}\text { Poss } \\
\text { Pro. }\end{array}$ & $\begin{array}{l}\text { Reflexive } \\
\text { Pronouns }\end{array}$ & Obj Pro. \\
\hline \multicolumn{6}{|c|}{ Singular Forms } \\
\hline $1^{\text {st }}$ & I & My & mine & Myself & $\mathrm{Me}$ \\
\hline $2^{\text {nd }}$ & You & Your & yours & Yourself & You \\
\hline 3rd (m) & $\mathrm{He}$ & His & his & Himself & Him \\
\hline 3rd (f) & She & Her & hers & Herself & Her \\
\hline 3rd (In.) & It & Its & its & Itself & It \\
\hline \multicolumn{6}{|c|}{$\underline{\text { Plural Forms }}$} \\
\hline $1^{\text {st }}$ & We & Our & ours & Ourselves & Us \\
\hline $2^{\text {nd }}$ & You & your & yours & Yourselves & You \\
\hline $3^{\text {rd }}$ & They & their & theirs & Themselves & Them \\
\hline
\end{tabular}

Note: $\mathrm{m}=$ male, $\mathrm{f}=$ female, In.=Inanimate

Pronoun forms that were considered too ambiguous such as the $2^{\text {nd }}$ person plural form and several $3^{\text {rd }}$ person inanimate forms were excluded from the study and are crossed out in Table 3.

\subsection{Research Sites and Respondents}

Two kindergartens located in Malaysian university campuses which were designated as research or experimental kindergartens were involved in the study. The students in this study who attend these kindergartens are mostly Malay and children of staff of the universities involved. A total of 53 children were involved in the study. Of these 53 children, 40 participated in the Pronoun Elicitation Task, some of whom were also observed for their use of pronouns. Information regarding the use of pronouns by the remaining 13 students was also obtained through observations or from teacher interviews. The four teachers involved in this study were directly responsible for the children who participated in the study. All four teachers, two each from each kindergarten, hold basic degrees with one pursuing her doctorate. The teachers all have at least basic functional proficiency in the English language. The teachers were interviewed in pairs after the questionnaires, multiple choice pronoun elicitation task and teacher observations were conducted. In this study, information regarding the students' language proficiency and their socio-economic background as reflected by the profession of their parents are obtained.

\subsection{Instruments}

Three instruments were used to collect data in this study. The first was a multiple choice question task - referred to in this study as the Pronoun Elicitation Task - which was administered to the forty children. The second was a checklist used during the teachers during their observations. Only 15 children were observed as it was felt that it would be too difficult for the teachers to observe too many children because of the intensive nature of the observations and the use of checklists. Teachers were also interviewed in order to obtain a general reaction to the extent students were familiar with pronoun use as well as to elicit suggestions on how pronouns can be taught to the children.

\subsubsection{Elicitation Task on Acquisition of English Pronouns}

The Elicitation Task on acquisition of English Personal Pronouns is a multiple choice question task that consisted of 33 items intended to elicit the children's knowledge or familiarity of pronouns. Each item was made up of a sentence containing a blank which the children had to fill by selecting one of three pronouns provided. Each sentence was illustrated to help children better understand its meaning. Teachers also assisted in reading out the sentence and the distractors to the students.

The three options for each sentence consist of the correct answer or the key as well as two other options that are similar in person reference to the key. For example, if the correct answer or key is $m e$, then the other options or distractors may be any two of the following: $I, m y$, or mine. The reflexive pronoun, myself in this particular instance, is not used as a distractor in order to avoid students selecting the pronoun because of its obvious difference in form. Some sentences also contained options that are nonsense pronouns such as hisself. This is done to anticipate errors in pronouns as well as error forms that students may make. All sentences were printed in a booklet and given to each child. As described earlier, teachers were instructed to read the sentences as well as the options and instruct the children to circle their preferred response.

\subsubsection{Teacher Observation and Checklist}

A questionnaire and a checklist were used to obtain information regarding the kinds of pronouns used by the children. The questionnaire required the teachers to provide demographic information regarding the children under their care. It 
also required the teachers to provide a general overview of students' use of pronouns.

The major intention of the teacher observation was to identify the kinds of pronouns actually used by the children. The observation was conducted over a period of 10 school days and a checklist was used to indicate whenever an English language pronoun was used. Teachers were instructed to take note of pronoun use in natural situations and not while reading texts containing pronouns or when the lesson focused on pronouns. As the observations required intensive involvement on the part of the teachers, only 15 children from the two kindergartens were observed.

\subsubsection{Interview with Teachers.}

Interviews were conducted after the multiple choice question tasks and the teacher observations. Teachers were asked to identify error forms that they noticed throughout the duration of the study and provide a general assessment of whether they thought the students were able to use the pronoun forms correctly. Their responses regarding the teaching of English to kindergarteners were also elicited.

Demographic information of the children which can be relevant to the research such as language proficiency, socioeconomic background and language spoken at home were also obtained with the assistance of the teacher and through the questionnaire and interviews. Similarly, an indication of the teachers' own language proficiency is obtained through the interview.

\subsection{Research Procedure.}

After the kindergartens and students were identified, the pronoun elicitation task was the first instrument administered. Teachers were also asked to help the researchers to make ten observations of selected students in their class to observe the use of English personal pronouns among the students. Concurrently, the teachers were also asked to record their perception of their students' ability in using pronouns. Finally, teachers were then interviewed to obtain their responses regarding the kind of errors in the use of personal pronouns made by their students.

Analysis of data consisted mainly of examining accuracy rates on the pronoun elicitation task as well as comparing these rates to the acquisition sequence proposed by Owens Jr. (2008). Error forms made by the students were also identified based on teacher observations, interviews as well as specific questions in the elicitation task that contained intentional nonsense forms. These errors as well as other relevant information were also used in helping to establish an acquisition sequence for personal pronouns.

Finally, in the fourth phase of the study, findings from the study were used in order to formulate general suggestions in teaching English personal pronouns to Malaysian ESL children. These suggestions took the form of a teaching guide and module for kindergarten teachers and administrators.

\section{Results}

The acquisition of pronouns among children is discussed in terms of accuracy rates in the multiple choice item tasks, and data from the checklist during teacher observations as well as from the interviews with teachers.

\subsection{Accuracy Rates from Elicitation Task}

In general, the children's overall performance on the elicitation task can be described as average. On a possible total score of 33, the Mean score was 15.25 with a Standard Deviation of 6.428. The children's accuracy rates according to individual pronouns, case as well as person reference are reported in Tables 4, 5 and 6 respectively.

In Table 4, only the personal pronouns that were correctly chosen by more than $50 \%$ of the children are ranked in order of accuracy. Note that the pronoun it and its forms were excluded as these pronouns were distinctly different from the personal pronouns that referred to animate objects.

Table 4. Pronoun rank according to accuracy rates

\begin{tabular}{llll}
\hline Rank & Type & Pronoun & $\begin{array}{l}\text { Percent } \\
\text { correct }\end{array}$ \\
\hline 1 & 1st per. ref. (sg) & Myself & 85 \\
2 & 3rd per. subj. & She & 65 \\
3 & 1st per. obj. (sg) & Me & 60 \\
4 & 3rd per. obj. & Them & 57.5 \\
5 & 1st per. poss adj (sg) & My & 55.8 \\
& 2nd per. subj. & You & 55.8 \\
7 & 1st per. poss (pl) & Ours & 52.5 \\
8 & 1st per. subj. (sg) & I & 50 \\
& 1st per. ref. (pl) & Ourselves & 50 \\
& 2nd per. poss obj. & Yours & 50 \\
& 3rd per. obj. (sg m) & Him & 50 \\
& 3rd per. obj. (sg f) & Her & 50 \\
& 3rd per. ref. (pl) & Themselves & 50 \\
\hline
\end{tabular}

Note: per. $=$ person, subj. $=$ subject, obj. $=$ object, poss $=$ possessive, $\mathrm{pl}=$ plural, $\mathrm{sg}=$ singular $\mathrm{m}=$ male, $\mathrm{f}=$ female, $\operatorname{adj}=$ adjective 
From the list of pronouns in Table 4.10, it is noted that only 13 pronouns were correctly selected by 50 percent or more of the children while the other pronouns had accuracy rates that ranged from as low as 22.5 to 48.8 percent.

In Table 5, pronouns were grouped according to case (nominative, accusative or genitive) or kind (possessive adjective or reflexive) and ranked based on accuracy of responses

Table 5. Pronoun case and type rank according to average accuracy rates

\begin{tabular}{llll}
\hline Rank & Case & Pronouns & $\begin{array}{l}\text { Percent } \\
\text { correct }\end{array}$ \\
\hline 1 & Subj. (Nom.) & I, you, he, she, we, they & 52.4 \\
2 & Obj. (Acc.) & Me, you, him, her, us, them & 51.5 \\
3 & Reflexive & Myself, yourself, himself, herself, themselves & 49.4 \\
4 & Poss. (Gen.) & Mine, yours, his, hers, theirs & 43.7 \\
5 & Poss. Adj. & My, your, his, her, their & 37.6 \\
\hline
\end{tabular}

Table 5 clearly shows that the Nominative and Accusative cases seem to be more familiar to the children as both had accuracy rates of more than 50 percent.

In Table 6, pronouns were grouped according to person reference and the percentage of correct responses for each group was calculated and ranked.

Table 6. Pronoun person reference rank according to average accuracy rates

\begin{tabular}{llll}
\hline Rank & Person & Pronouns & $\begin{array}{l}\text { Percent } \\
\text { correct }\end{array}$ \\
\hline 1 & 1st per. (sg) & I, me, my, mine, myself & 57.6 \\
2 & 3rd per. (pl) & they, their, them, theirs, themselves & 48.8 \\
3 & 1st per. (pl) & we, us, our, ours, ourselves & 46 \\
4 & 2nd per. & you, your, yours, you, yourself & 45.5 \\
5 & 3rd per. (sg, f) & she, her, hers, her, herself & 43.3 \\
6 & 3rd per. (sg, m) & he, his, him, his, himself & 39.5 \\
\hline
\end{tabular}

From Table 6, it is noted that the 1st person singular reference is the most accurately used with a 57.6 percent accuracy rate. This is followed by the $3 \mathrm{rd}$ person plural, 1 st person plural and 2 nd person pronoun reference.

\subsection{Checklists}

Teachers were asked to observe students for ten sessions to note the pronouns that were used in natural communication in the classroom or at play. Teachers were also asked to fill a questionnaire on the kinds of pronouns they felt were used by the same students. Sixteen checklists and questionnaires were returned by teachers from the two kindergartens. From these 16 checklists, the teachers indicated that four of the children did not use pronouns in natural communication during the ten observations. The responses from the checklists, however, indicated that the pronouns $I$ and you followed by he and she were the most commonly used.

In many of the questionnaires and at least one checklist, the full complement of first person pronouns (I, my, mine, me, and myself) were reported as being used. Various forms of the other more common pronouns such as you, he and she were either not observed or not reported as being used by the teachers. These forms were mostly the reflexive and possessive forms and followed to a lesser extent, by the objective pronoun form. Interestingly, however, the reflexive pronoun myself was reported to be used more frequently than other reflexive pronouns, many of which were not used at all. This seems to correlate with the relatively higher accuracy rate for the pronoun myself in the pronoun elicitation task.

\subsection{Error Forms}

During the interviews, teachers from the two kindergartens mentioned specific instances of errors. In one example, the sentence Me want to go is used instead of I want to go. It is not clear why this error is made although one can theories that the student may believe that first person pronouns - especially I, me, my and mine - can be treated as a name referring to the first person and is also interchangeable.

Other errors that were reported include My one is at home when talking about a doll, and the response of $m e$... me, when asked whose book is this, and You table when asked whose table is this? One of the teachers also noted that the students preferred to use the names of their friends instead of pronouns. 


\subsection{Pronoun Development.}

The accuracy rates obtained from the elicitation tasks as well as information from the checklists are used to construct a hypothetical sequence of acquisition for Malaysian ESL children learning English personal pronouns. In Figure 8, the acquisition rates of groups of pronouns are compared against the acquisition rate proposed by Owens Jr. (2008).

\begin{tabular}{|c|c|c|c|c|c|c|c|}
\hline $\begin{array}{l}\text { Observation } \\
\text { and } \\
\text { Checklist }\end{array}$ & $\begin{array}{l}\text { I, } \\
\text { you, } \\
\text { he, } \\
\text { she }\end{array}$ & $\begin{array}{l}\text { Subjective } \\
\text { other than I, } \\
\text { you, he and } \\
\text { she }\end{array}$ & $\begin{array}{l}\text { First } \\
\text { person sg } \\
\text { other than } \\
\text { I and me }\end{array}$ & $\begin{array}{l}\text { Objective } \\
\text { other than } \\
\text { me }\end{array}$ & $\begin{array}{l}\text { Poss. Adj } \\
\text { other } \\
\text { than my }\end{array}$ & $\begin{array}{l}\text { Possessives } \\
\text { other than } \\
\text { mine }\end{array}$ & $\begin{array}{l}\text { Reflexives } \\
\text { other than } \\
\text { myself }\end{array}$ \\
\hline
\end{tabular}

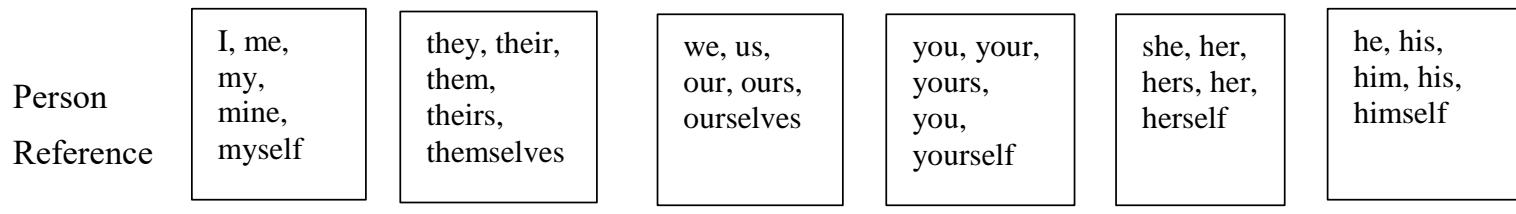

Case/

Type

\begin{tabular}{|l|l|}
\hline $\begin{array}{l}\text { Subjective: } \\
\text { I, you, he, she, } \\
\text { we, they }\end{array}$ & $\begin{array}{l}\text { Objective : } \\
\text { Me, you, } \\
\text { him, her, us, } \\
\text { them }\end{array}$ \\
\hline
\end{tabular}

Possessive:

Mine, yours,

his, hers, theirs

\section{Possessive}

Adjective: My, your, his, her, their

Individual Myself, she, me, them, ours, they, you (obj),

Pronouns

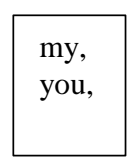

Owens Jr.
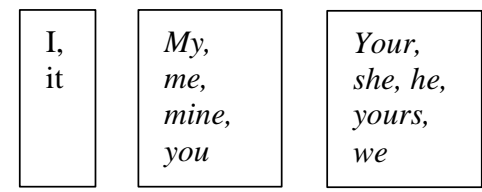

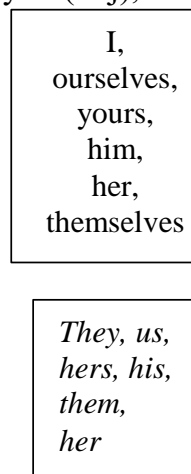

her

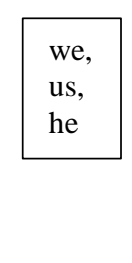

$$
\begin{aligned}
& \text { Its, our, him, } \\
& \text { myself, yourself, } \\
& \text { ours, their, } \\
& \text { theirs }
\end{aligned}
$$

hers,

theirs

Acquisition/Development Sequence

Figure 1. Comparison of acquisition/development sequence based on collected data

In Figure 1, the first person personal pronoun $I$ can be seen as being acquired relatively early. Although as an individual pronoun it is not as accurately used as some other pronouns, nevertheless it belongs to several categories which, as a group, are more accurately used. Other first person personal pronouns are also acquired relatively early. This is most obvious based on the observations and checklist data.

In terms of person reference, it is interesting to note that accuracy rates for the third person plural forms is higher than on the first person plural pronoun forms. More surprisingly, reflexive pronouns also have a relatively higher accuracy rate. Personal pronoun forms that had low accuracy included the possessive adjectives his and her, third person singular pronouns in general, and possessive pronouns in general.

In comparing the accuracy rates obtained in this study and the acquisition rate proposed by Owens Jr. (2008), several similarities and differences can be noticed. The similarity is in how the first person pronoun is acquired early. This is clearly seen in the Owens Jr. sequence and strongly implied in the data obtained in the study. Similarly, in terms of concepts, the subjective case is also acquired early in the Owens Jr. sequence and the data obtained through this study.

Differences, however, are seen in terms of the reflexives as well as the relatively higher rate of accuracy for third person plural pronoun forms (we, our, ours, and us). Both these differences are rather surprising and unexpected. One possible explanation for the earlier familiarity of the reflexives may be found in the kindergarten curriculum itself. The topic Myself is one of the topics in the curriculum and teachers may give inordinate emphasis to this reflexive. As for the third person plural pronoun, a possible reason for its relatively higher rate of accuracy could be because of the kindergarten setting itself. The formal kindergarten setting allows for greater socialization among the students and may encourage greater use of the third person plural pronoun. 


\section{Discussion}

With respect to acquisition, there is indication from the results of the study that first person pronouns, especially $I$ and $m e$, are acquired generally early relative to other pronouns. Although none of these pronouns occupy the most accurately used pronoun position according to the pronoun elicitation task, nevertheless, first person pronouns as a group are, for the most part, accurately used by many of the students. A second type of personal pronoun that has a relatively high accuracy rate is the 2 nd person pronoun you. This is observed not so much in the accuracy of responses in the pronoun elicitation task, but more so through feedback from the checklist and the teacher observations where both you and $I$ are reported as commonly used pronouns. Some the teachers interviewed in the study refer to these pronouns as "common" pronouns.

The students' greater accuracy in the use of the pronouns $I$ and you compared to other pronouns is not surprising. Rispoli (2005, p. 95) argues that acquisition of first and second person is easier than that of the third person pronoun as the third person pronoun can be replaced by a noun-head whereas the former two cannot. Hence, while the pronoun he in He lives here can be replaced by The boy, for example, it is not possible to replace the pronouns you and $I$ in the sentences You live here and I live here respectively. Therefore, it can be argued that there is greater markedness with the pronouns $I$ and you and because they are not easily replaced or substituted by other words, they will need to be acquired by learners of the language.

It is also interesting to note that the results of the study indicate that the reflexive pronoun myself occupies the most accurately used pronoun position in the list of pronouns in Table 4. The pronoun is also noted as a commonly used pronoun by many teachers as indicated from the teacher observation checklist. While it is difficult to explain the reason for its prominence compared to other reflexive pronouns and even to other pronouns in general, it should be noted that the National Curriculum for Kindergartens in Malaysia, which emphasises a thematic approach, lists Myself as one of the seven themes of the curriculum. This inordinate focus on Myself compared to the other personal pronouns may therefore have an effect on the familiarity of this pronoun among the children in this study.

\section{Conclusion}

This study focused on a specific grammatical sub-system - the personal pronoun - of the English language and how it is acquired by ESL students in two Malaysian kindergartens. The choice of the personal pronoun was because it is generally systematic and can have a bearing on concepts that are relevant to child development with two language related concepts, case and person reference were given greater focus in this study.

The approach taken in this study was generally cross-sectional although the observations conducted and the questionnaires filled by the teachers were done over a specific period of time. Acquisition studies, especially those that intend to determine a sequence of acquisition, may require a more extensive, ethnographic and longitudinal study lasting several years. Nevertheless, despite this, cross sectional studies such as these can still provide insights into the acquisition process. The acquisition sequence for English personal pronouns among Malaysian ESL children as presented earlier is an indicative sequence based on various data sources and can be useful in trying to understand the language acquisition process among ESL children especially, but perhaps not limited to, personal pronouns.

Generally, there does not seem to be an obvious difference between the English language personal pronoun acquisition sequence proposed by Owens Jr. (2008) and the sequence suggested by the findings in this study. Because of this similarity, it can be argued that in so far as personal pronouns are concerned, curricula used to teach English speaking children can be used for Malaysian ESL children as well. Acquisition of pronouns may be based on the extent of their use in teaching materials such as story books as well as their natural use by teachers and the children themselves in the classroom and in play. A strange finding of this study was the relatively high accuracy rate of the reflexives, especially myself. This, however, may be indicative of the present curriculum in which "Myself" is a theme and consequently teachers may have given it additional emphasis and children may have selected it because of their familiarity to the pronoun.

A major conclusion that can be made from the results of this study is that more "common" pronouns such as $I$, you, and $m e$ are acquired early among Malaysian children learning English as a second language. The implication of this is that intervention must be provided to children at this age who are not yet able to accurately use these pronouns. In learning English as a second language, the inability of a child to use the pronouns $I$ and you may indicate a developmental problem that needs to be addressed.

There is also indication from the data that children focus on their self as they acquire pronouns that refer to the first person earlier than those that refer to the second or third persons. This finding is not surprising as it reflects the developing ego, self-identity or self-awareness of the child. From a teaching perspective, this may give credence to the grouping of pronouns according to person reference rather than more common language related concepts such as case, possessive adjectives and reflexives. Often, in teaching a language, the perspective of the language is made the central reference as teachers organize their presentations according to the structure of the language. This language focus emphasizes concepts such as Nominative and Accusative position pronouns being presented because they occupy the subject and object positions of the sentence respectively. However, the data in this study indicates that children's thought processes may organize their experiences according to a more social-psychological context in which person - i.e. first person, second person etc. - may have a stronger influence than the more linguistic concept of case.

Thirdly, there are error forms that may need direct intervention in order to be corrected. The fact that some of these error forms (e.g. my one) are observed even among older children may indicate that they are being reinforced through socialization among non-native ESL speakers. Other possible causes of these errors may include the use of a dual language emphasis at the kindergarten (Abdullah et al., 2015). Early intervention at the kindergarten level, in this respect, 
may be able to prevent such error forms from taking root and becoming fossilized in children's speech.

Finally, the presentation of personal pronouns to children learning English as s second language should also consider groupings that can address specific issues or concerns as observed in this study. For example, as the students were observed to use names more often than pronouns, the introduction of third person singular pronouns such as he and she should be done in situations where the discourse will include names followed by the relevant pronouns so that these third person pronouns are not confused by the children as names. Similarly, the specific errors made such as my one and me instead of $I$ as indicated by the reports from the teachers can be addressed through enhancement of the correct forms through oral emphasis, recasts or gestures during teacher-led play or demonstrations.

\section{References}

Abdullah, A. C., Tan Kok Eng, Chitra K.M. Krishnan Adiyodi, Yeoh Phaik Kin, \& Regina Joseph Cyril. (2015). Chapter 4: Preschool. In English Language Reform in Malaysia: The Roadmap 2015-2025. Kuala Lumpur: Ministry of Education, Malaysia.

Arshad Abd.Samad, Fauziah Hassan, Jayakaran Mukundan, Ghazali Kamarudin, Sharifah Zainab Syd Abd. Rahman, Juridah Md. Rashid, Malachi Edwin Vethamani. (2002). The English of Malaysian School Students (EMAS) Corpus. Serdang: Universiti Putra Malaysia Press.

Berry, R. (2012). English Grammar. New York: Routledge.

Charney, R. (1980). Speech roles and the development of personal pronouns. Journal of Child Language, 7, 509-528.

Chiat, S. (1986). Personal pronouns. In P. Fletcher \& M. Garman (eds), Language acquisition: Studies in first language development, 339-55. Cambridge: Cambridge University Press.

Cruttenden, A. (1977). The acquisition of personal pronouns and language 'simplification'. Language and Speech, 20, 3, 191-197.

Dale, P. S. \& Crain-Thoreson, C. (1993). Pronoun reversals: Who, when, and why? Journal of Child Language 20, 57189.

Fraiberg, S. \& Adelson, E. (1977). Self-representation in language and play. In, S. Fraiberg, Insights from the blind (248270). New York: Basic Books, Inc.

Gestwicki, C. (2011). Developmentally appropriate practice: Curriculum and development in early education. $4^{\text {th }}$ Ed. Belmont, CA: Wadsworth Cengage Learning.

Huxley, R. (1970). The development of the correct use of the subject personal pronouns in two children. In Flores d'Arcais, G. B., and Levelt, W. J. M. (eds.), Advances in Psycholinguistics (New York).

Ministry of Education Malaysia (2015). English language education reform in Malaysia: The Roadmap 2015-2025. Putrajaya: Ministry of Education Malaysia.

Morgenstern, A. (2012). The self as Other: Selfwords and pronominal reversals in language acquisition. In Lorda \& Zabalbeascoa. Spaces of Polyphony (57-72). New York: John Benjamins Publishing.

Owens Jr., J. E. (2008). Language Development: An Introduction. New York: Allyn \& Bacon.

Rispoli, M. (2005). When children reach beyond their grasp: Why some children make pronoun case errors and others don't. Journal of Child Language, 32,93-116

Waterman, P. \& Shatz, M. (1982). The acquisition of personal pronouns and proper names by an identical twin pair. Journal of Speech, Language, and Hearing Research. 25, 149-154.

Wells, G. (1985). Language development in the pre-school years. Cambridge, England: Cambridge University Press.

Wong, B. E. \& Liu, J. C. (2008). The Acquisition of Gender, Number and Case in English Personal Pronouns. In Jacobson, R. (Ed.) The Pulse of a Malaysian University (101-119). New York: Peter Lang. 